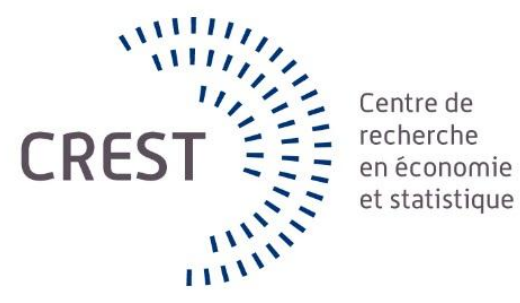

Série des Documents de Travail

\title{
$n^{\circ}$ 2014-42
}

\section{More harm than good? Sorting effects in a Compensatory education program} Laurent DAVEZIES
Manon GARROUSTE

Les documents de travail ne reflètent pas la position du CREST et n'engagent que leurs auteurs. Working papers do not reflect the position of CREST but only the views of the authors.

\footnotetext{
${ }^{1}$ CREST, Malakoff, France. E-mail: laurent.davezies@ensae.fr

${ }^{2}$ CREST, INED, Université Paris I Panthéon-Sorbonne, E-mail: manon.garrouste@ensae.fr
} 


\title{
More harm than good? Sorting effects in a compensatory education program
}

\author{
Laurent Davezies* $\quad$ Manon Garrouste ${ }^{\dagger}$
}

This version: December 2014

\begin{abstract}
In this paper, we provide evidence that compensatory education policies that target schools in socially deprived areas are likely to create a negative signal resulting in a sorting effect. We investigate this effect by analyzing the French "Réseaux ambition réussite" (RAR) program, which targeted low-achieving and socially disadvantaged junior high schools between 2006 and 2011. We use an original geocoded individual data set and a regression discontinuity identification strategy to assess the causal effect of the RAR program on families' school choice. We find that individuals do adjust to school-based compensatory education policies, since they tend to avoid schools that enter the RAR program by enrolling in the private sector. We also find that the RAR program increases social segregation across schools, since the most socially advantaged individuals tend to avoid schools that enter the RAR program more than other pupils, by enrolling in the private sector instead.
\end{abstract}

Keywords: Education, Education Policy, Treatment Effect Model, Regression Discontinuity JEL classification: I24, I28, C21

\footnotetext{
${ }^{*}$ CREST, laurent.davezies@ensae.fr

${ }^{\dagger}$ INED, Université Paris I Panthéon-Sorbonne, CREST, manon.garrouste@ensae.fr
}

The authors would like to thank the statistical service of the French Ministry of Education (DEPP), in particular Jean-Paul Caille, Agnès Brizard, Sylvie Le Laidier, Cédric Afsa and Caroline Simonis-Sueur for their help and great support, as well as the participants to the DEPP's workshop for their comments. For helpful remarks and comments, they are grateful to Nicolas Jacquemet, Miren Lafourcade, Son-Thierry Ly and seminar participants in CREST, Paris 1 University, Catanzaro, Toulouse and in the French Ministry of Housing and Territorial Equality. The authors gratefully acknowledge financial and material support from the statistical service of the French Education Ministry. This work was financially supported by the Investissements d'Avenir grant (ANR-11-IDEX-0003/Labex Ecodec/ANR-11-LABX-0047). 


\section{Introduction}

Compensatory education policies aim at offsetting educational inequalities between socially and academically disadvantaged children and more advantaged ones. They first appeared in the 1960's when mass schooling and equal access to education were found to be insufficient to ensure equal opportunity in developed countries. The fundamental idea is to provide some sub-population with additional resources in order to achieve equal opportunity through unequal treatment. Such education programs traditionally target schools in socially and academically deprived areas. For that reason, they are referred to as placebased (or school-based) programs, as opposed to individual-based ones. Title I of the Primary and Secondary Education Act in the US, Education Priority Areas in the UK or "Zone d'éducation prioritaire" (ZEP) in France are examples, among many, of such policies. Such programs exist worldwide and they usually represent a significant part of public spending in education. The sole Title I program represents around 14 billion dollars per fiscal year. In France, compensatory education corresponds to about 1 billion euros each year. In both cases, the additional spending over the number of recipients represents about $10 \%$ of the annual spending per pupil.

Providing underprivileged schools with (sufficiently) more resources is expected to improve pupils' performance and, ultimately, to close the educational gap. ${ }^{1}$ The empirical evidence, however, is mixed. First, the empirical relationship between school resources and pupils' performance is the subject of an extensive debate. Hanushek (2003) finds it to be weak, whereas Krueger (2003), Hedges et al. (1994) and Dewey et al. (2000) find a positive and quite large link. Second, empirical evaluations of school-based compensatory education measures have not reach a consensus either. Programs that intervene very early in primary or in pre-primary education seem to have positive and somewhat large effects on pupils' performance (Dobbie and Fryer, 2011; Shapiro and Moreno, 2004; Tokman, 2002). But many place-based compensatory education programs have limited results. Title I in the US proved to have a modest overall impact on pupils' outcomes (Borman and d'Agostino, 1996) and may even have had adverse effects according to Van der Klaauw (2008). In the UK, Machin, McNally and Meghir (2004 and 2010) provide an evaluation of the Excellence in Cities program and find a positive but modest impact on pupils' performance (for math scores only) and a reduction of absenteeism. In France, Bénabou, Kramarz and Prost (2009) show that the ZEP program had no impact on pupils' achievement. Beffy and Davezies (2013) find a negative impact of the "Réseaux ambition réussite" program on academic achievement.

Some reasons may explain why such policies have limited empirical results. First, some claim that financial support is scattered across too many schools for a too low final amount per pupil. Van der Klaauw (2008) explains for instance that "almost all schools are eligible to at least some Title I funds". In France, more than 1 pupil out of 7 was enrolled in a

\footnotetext{
${ }^{1}$ As a matter of fact, compensatory education policies were originally not meant to last. In France for instance, additional resources provided to ZEP schools were supposed to end once closed the achievement gap.
} 
compensatory education school in $2013 .^{2}$ Second, would spending per pupil be sufficient, it could be misallocated. Since these programs target schools and not individuals directly, it may be that they fail to reach the pupils who most need it or for whom it would be beneficial. Both arguments could explain small estimated effects. However, it seems much more difficult to explain why some empirical studies find negative results. In this paper, we want to explore the idea that general equilibrium effects may exceed partial equilibrium ones (Nechyba, 2003) and lead to adverse effects. One main limit of the literature on compensatory education is that it usually focuses on schools and ignores individual adjustments to school-based policies. Yet endogenous sorting of individuals across schools or across neighborhoods is expected to significantly impact place-based policies. A growing theoretical and empirical literature shows first that individuals do adjust to a change in public good provision by moving or changing schools (Ferreyra, 2007; Hsieh and Urquiola, 2006 Urquiola, 2005; Urquiola and Verhoogen, 2009) and second that they incorporate these adjustments in their decisions (Epple, Romer and Sieg, 2001).

In this paper, we analyze the impact of place-based compensatory education on individual sorting across schools. To our knowledge, our paper is the first attempt to evaluate sorting effects due to a compensatory education program and, doing so, to include general equilibrium effects into the analysis of compensatory education policies. Studying such effects is crucial first because, if they are sizeable, then one need to take them into account when evaluating compensatory education policies. Sorting effects would affect the composition of treated schools and thus the estimated impact of the treatment. Targeting schools in academically and socially deprived areas may create a negative signal resulting in a sorting effect. In that case, more advantaged individuals would tend to avoid selected schools because they are labeled as low-achieving ones. Thus, this could explain partly why estimated effects are small or even negative. The fact that more advantaged pupils select themselves out of treated schools, for instance, may drive part of the overall limited effect. Second, there are non negligible education policy implications. Policy makers may want to be aware of such general equilibrium effects when designing compensatory education programs.

To answer the question, we use the context of the French "Réseaux ambition réussite" (RAR) program, which targeted very low-achieving and socially disadvantaged junior high schools between 2006 and 2011. We try and assess the causal impact of the program on families' school choice. To do so, we use an original geocoded individual data set and a regression discontinuity identification strategy. More precisely, we ask wether living in the vicinity of a RAR school affects individual school choice, using an exogenous eligibility scheme into treatment. We find that living near a RAR junior high school decreases the probability to attend the closest school and increases the probability to go to a private school for pupils living near a school just above the eligibility thresholds. We also find that the RAR program increases social segregation across schools, since pupils from more advantaged background are more likely to attend a private school when they live near a RAR junior high school.

\footnotetext{
${ }^{2}$ Source : French National Education Ministry.
} 
The paper is organized as follows. We briefly describe the French education system and the RAR program in the next section. Section 3 presents the data. The identification strategy and the model are detailed in Section 4.1 and 4.2. Section 5 presents the results. Section 6 concludes.

\section{A brief description of the French education system}

In France, education is compulsory from 6 to 16 years old. The French school system consists of 5 years of primary school (age 6 to 10), then 4 years of junior high school called "collège" (age 11 to 14) and 3 years of high school called "lycée" (age 15 to 17).

French primary and secondary education is based on a catchment area system; each pupil is assigned to a public school according to where she lives. Junior high school catchment areas are delimited at the local level by the "département" ("conseil général") and each area contains only one junior high school. The catchment area school represents families' default school option and they have two outside options. They can either send their child to a private school. Most private schools are largely subsidized by the State and follow the same curriculum than public schools (except for religious instruction), so that they constitute a commonly used outside option. Or they can ask for another public school through a special dispensation. Dispensations are granted by the regional education authority director on the basis of (in order of priority) medical reasons, scholarship, siblings, distance, special academic tracks. Pupils living in the catchment area have the priority and dispensations are only accorded if all places were not fulfilled by them. ${ }^{3}$

The 2006 French compensatory education reform created a new structure called the "ambition success" networks ("Réseaux Ambition Réussite" or RAR). The program targeted the most disadvantaged junior high schools. Each network consisted in one junior high school and in the primary and infant schools of the catchment area. The network was managed by an executive committee, composed of the head of the junior high school, the heads of the elementary and infant schools and the Ministry of National Education inspector responsible for the schools district. The aim of these networks was to build or reinforce the relationships between schools within the network in order to improve educational outcomes for all pupils. To achieve this goal, each network had to define an educational project through a four to five year contract. To do so, RAR junior high schools were provided with additional resources in order to finance 1000 extra teachers and 3000 teaching assistants. 249 junior high schools were selected to become the center of a RAR from the beginning of the 2006 school year.

The selection of junior high schools in RAR was made on the basis of objective criteria which were evaluated at the national level during the 2004/2005 school year. These criteria

\footnotetext{
${ }^{3}$ The catchment area system was partly relaxed in 2007. This was supposed to give families more freedom in school choice. The increasing number of dispensation demands made that the size of RAR schools decreased (Fack and Grenet, 2013). However, as long as there is no more dispensation demands above or below the eligibility thresholds in the absence of the RAR program, this does not constitute a confounding factor for our analysis.
} 
were the proportion of children from disadvantaged social background in the school and the proportion of pupils having repeated two grades or more when they enter 6th grade. More precisely, junior high schools had to have at least $67 \%$ of pupils from disadvantaged background $^{4}$ and at least $10 \%$ of pupils having repeated twice or more at 6 th grade to become eligible to the program. ${ }^{5}$ These thresholds were arbitrarily defined so that selected schools would represent the $5 \%$ most socially and academically disadvantaged pupils. The list of eligible schools was approved by the Minister of National Education. Then some further adjustments made that some schools that were eligible did not enter the treatment and some schools below the thresholds did enter it.

The additional cost of RARs has been estimated to around 325 million euros for the budget year 2008. It corresponds to about 811 additional euros per pupil, that is approximately $10 \%$ of the annual spending per junior high school pupil. $90 \%$ of the additional cost correspond to the funding of additional teachers and assistants.

\section{The data}

To analyze the school choice of pupils potentially affected by the program, we use exhaustive micro-level data provided by the statistical service of the French Ministry of Education, both at the pupil and school levels. First we use an exhaustive individual data set of French pupils entering 6th grade in 2006 and 2007. We have information on their family background through their parents' occupations, we know their sex, age, origin and whether they benefit from a scholarship or not. We also observe which primary school they attended in 5th grade, with its exact geographic location. We know which junior high school they attend in 6th grade, whether this is a public school or a private one and whether this is a RAR school or not.

A second source of data comes from an exhaustive data set at the school level in which we observe every mainland France public junior high schools with their exact geographic location. ${ }^{6}$ For each of these schools, we observe the proportion of pupils from disadvantaged backgrounds and the proportion of repeaters when entering 6th grade as evaluated during the 2004-2005 school year, i.e. we observe whether each junior high school was eligible to the RAR program or not.

Combining those two data sets, we are able to define each pupil's closest public junior high school, using the smallest (Euclidean) distance to their primary school. Because we don't know the exact location of pupils' home, we approximate their location by the location of their primary school. Note that we don't know their catchment area junior high school either, but we consider the closest public junior high school to their primary school instead.

\footnotetext{
${ }^{4}$ Pupils from disadvantaged backgrounds were defined as children of blue collars, retired blue collars, retired white collars or unemployed.

${ }^{5}$ Some regional education authorities used an additional measure of pupils' achievement at the beginning of 6 th grade. But since this measure was not available in every school, it is not used in this analysis.

${ }^{6}$ In the school-level data base, we only consider public junior high schools here, because private schools were not concerned by the program. However, we do observe pupils enrolled in a private school in the individual-level data base.
} 
We believe this is a convincing proxy for families' default school option. Moreover, as long as there is no systematic bias in our measure of closest school, then the only consequence is a loss of precision and an attenuation bias.

We restrict our sample to pupils living in mainland France ${ }^{7}$ and we thus observe 1098636 individuals, with 531729 entering 6th grade in 2006 and 566907 in 2007. Among them, 28517 are enrolled in a RAR junior high school, that is $3 \%$ of the sample. More than $50 \%$ of pupils are going to their closest public junior high school, while $26 \%$ are attending another public school. Around $20 \%$ of 6 th grade pupils are attending a private school.

Treated schools were selected because they belong to socially and academically disadvantaged areas. Consequently, living near a RAR junior high school is not exogenous. This is confirmed by some descriptive statistics. Tables 1 and 2 present a brief description of the sample. The first column of both tables gives the mean difference between pupils whose nearest junior high school is a RAR and pupils whose nearest junior high school is not a RAR. Pupils living near a RAR junior high school are very different from other pupils according to their observable characteristics; on average they are older than other pupils (0.12 year older, that is about 1.5 month older), they are less often born French, they come more often from a disadvantaged family (i.e. with a parent blue-collar, retired blue collar, retired white collar or unemployed), and they benefit more often from a scholarship. The three following columns give the same mean differences for different windows around each threshold in order for samples to be comparable with the three last columns. Note that significant differences still hold (although they are smaller) when we focus on observations just around the thresholds. Of course such differences are not surprising, since the RAR program aimed at targeting pupils in socially disadvantaged areas. But they highlight the fact that a naive comparison between pupils living in the vicinity of a RAR school and other pupils would lead to a selection bias, since they would be very different populations even in the absence of the program. Then the three remaining columns present the mean differences between pupils living near a public junior high school that is just below or just above the eligibility thresholds, for different windows around the thresholds. These pupils are very much alike, since the last three columns of Tables 1 and 2 show almost no significant difference between the two sub-populations. Our identification strategy relies on the similarity between pupils living near schools just below and just above the eligibility thresholds. According to these descriptive statistics, they do not differ according to observed characteristics. This provides empirical support to the validity of our approach.

\section{Empirical strategy}

\subsection{Identification}

Our aim is to assess the role of the RAR program on possible sorting across schools. For that, we analyze the effect of living near a RAR junior high school on school choice. Consider the Rubin causal model framework (Rubin, 1974), where the treatment dummy

\footnotetext{
${ }^{7}$ Schools in overseas "départements" were almost automatically selected into the RAR program. So we would have no conter-factual individuals for pupils living in overseas departments.
} 
Table 1: Description of the sample around discontinuity $d^{L}$

\begin{tabular}{|c|c|c|c|c|c|c|c|}
\hline & \multicolumn{7}{|c|}{ Mean comparison of: } \\
\hline & \multicolumn{4}{|c|}{ Pupils living near a RAR vs not } & \multicolumn{3}{|c|}{ Pupils above vs below $d^{L}$} \\
\hline & Total & $\mathrm{h}=1$ & $\mathrm{~h}=2$ & $\mathrm{~h}=4$ & $\mathrm{~h}=1$ & $\mathrm{~h}=2$ & $\mathrm{~h}=4$ \\
\hline Sex & $\begin{array}{c}-0.01^{* * *} \\
(0.00)\end{array}$ & $\begin{array}{c}0.00 \\
(0.01)\end{array}$ & $\begin{array}{c}0.00 \\
(0.01)\end{array}$ & $\begin{array}{l}-0.01 \\
(0.01)\end{array}$ & $\begin{array}{c}0.02 \\
(0.02)\end{array}$ & $\begin{array}{c}0.01 \\
(0.02)\end{array}$ & $\begin{array}{c}0.01 \\
(0.01)\end{array}$ \\
\hline Born French & $\begin{array}{c}-0.04^{* * *} \\
(0.00)\end{array}$ & $\begin{array}{c}-0.04^{* * *} \\
(0.01)\end{array}$ & $\begin{array}{l}-0.02^{*} \\
(0.01)\end{array}$ & $\begin{array}{c}-0.02^{* * *} \\
(0.01)\end{array}$ & $\begin{array}{c}0.03 \\
(0.04)\end{array}$ & $\begin{array}{l}-0.01 \\
(0.03)\end{array}$ & $\begin{array}{l}-0.01 \\
(0.02)\end{array}$ \\
\hline Disadvantaged background & $\begin{array}{c}0.23^{* * *} \\
(0.01)\end{array}$ & $\begin{array}{c}0.03 \\
(0.04)\end{array}$ & $\begin{array}{c}0.04 \\
(0.02)\end{array}$ & $\begin{array}{c}0.06^{* * *} \\
(0.02)\end{array}$ & $\begin{array}{l}-0.05 \\
(0.06)\end{array}$ & $\begin{array}{l}-0.02 \\
(0.06)\end{array}$ & $\begin{array}{l}-0.04 \\
(0.04)\end{array}$ \\
\hline Scholarship & $\begin{array}{c}0.28^{* * *} \\
(0.01)\end{array}$ & $\begin{array}{c}0.14^{* * *} \\
(0.05)\end{array}$ & $\begin{array}{c}0.14^{* * *} \\
(0.03)\end{array}$ & $\begin{array}{c}0.15^{* * *} \\
(0.02)\end{array}$ & $\begin{array}{c}0.17^{* *} \\
(0.07)\end{array}$ & $\begin{array}{c}0.04 \\
(0.08)\end{array}$ & $\begin{array}{l}-0.04 \\
(0.05)\end{array}$ \\
\hline Nbr obs & $1,098,636$ & 6,671 & 15,868 & 31,180 & 6,671 & 15,868 & 31,180 \\
\hline
\end{tabular}

Source: MEN-MESR DEPP, FAERE 2006 and 2007

Note: $*(\mathrm{p}<0.10), * *(\mathrm{p}<0.05), * * *(\mathrm{p}<0.01)$. Standard errors in brackets are clustered at the closest junior high school level. Mean differences are estimated for different bandwidth of size $h$ around the $10 \%$ threshold.

Lecture: Pupils living in the vicinity of a RAR junior high school benefit more often from a scholarship (28 percentage point more) than pupils not living near a RAR junior high school. This difference is significant at the $1 \%$ level and remains significant when the sample is narrowed around the $10 \%$ threshold.

Table 2: Description of the sample around discontinuity $d^{F}$

\begin{tabular}{lcccc|ccc}
\hline \hline & \multicolumn{7}{c}{ Mean comparison of: } \\
& $\begin{array}{c}\text { Pupils living near a RAR vs not } \\
\text { Total }\end{array}$ & $\mathrm{h}=1$ & $\mathrm{~h}=2$ & $\mathrm{~h}=4$ & $\mathrm{~h}=1$ & $\mathrm{~h}=2$ & $\mathrm{~h}=4$ \\
\hline \multirow{2}{*}{ Sex } & $-0.01^{* * *}$ & -0.02 & -0.00 & 0.00 & -0.06 & -0.00 & -0.03 \\
& $(0.00)$ & $(0.03)$ & $(0.02)$ & $(0.01)$ & $(0.06)$ & $(0.05)$ & $(0.03)$ \\
\hline Age at 6th grade & $0.12^{* * *}$ & -0.04 & -0.05 & 0.02 & 0.04 & 0.07 & -0.06 \\
& $(0.00)$ & $(0.06)$ & $(0.04)$ & $(0.03)$ & $(0.10)$ & $(0.10)$ & $(0.06)$ \\
\hline Born French & $-0.04^{* * *}$ & -0.02 & -0.00 & -0.01 & -0.01 & 0.01 & 0.02 \\
& $(0.00)$ & $(0.02)$ & $(0.01)$ & $(0.03)$ & $(0.02)$ & $(0.02)$ & $(0.03)$ \\
\hline Scholarship & $0.28^{* * *}$ & 0.02 & -0.04 & $0.11^{*}$ & 0.17 & 0.06 & -0.11 \\
& $(0.01)$ & $(0.05)$ & $(0.05)$ & $(0.06)$ & $(0.10)$ & $(0.09)$ & $(0.08)$ \\
\hline Nbr obs & $1,098,636$ & 1,481 & 2,548 & 5,602 & 1,481 & 2,548 & 5,602 \\
\hline \hline
\end{tabular}

Source : MEN-MESR DEPP, FAERE 2006 and 2007

Note : * $(\mathrm{p}<0.10), * *(\mathrm{p}<0.05), * * *(\mathrm{p}<0.01)$. Standard errors in brackets are clustered at the closest junior high school level. Mean differences are estimated for different bandwidth of size $h$ around the $67 \%$ threshold.

Lecture: Pupils living in the vicinity of a RAR junior high school are less often born French (4 percentage point more) than pupils not living near a RAR junior high school. This difference is significant at the $1 \%$ level and turns not significant when the sample is narrowed around the $67 \%$ threshold. 
variable $T_{i}$ equals 1 if pupil $i$ lives near a RAR junior high school and 0 otherwise. Let us consider $Y_{i}$ the dummy outcome variable of school choice. $Y_{i}$ will represent different outcomes corresponding to the different possible school choices: being enrolled in the closest junior high school, being enrolled in a private school, or being enrolled in another public school. For those different variables, $Y_{i}(0)$ and $Y_{i}(1)$ are potential outcomes. $Y_{i}(1)$ is the value of the outcome when individual $i$ lives near a RAR and $Y_{i}(0)$ is the value of the outcome otherwise. The observed outcome is given by:

$$
Y_{i}=Y_{i}(0)+T_{i}\left(Y_{i}(1)-Y_{i}(0)\right)
$$

or:

$$
Y_{i}=\alpha_{i}+T_{i} \beta_{i}
$$

where $\beta_{i}$ represents the individual treatment effect: the individual effect of living near a RAR junior high school on school choice.

Because, as shown in the preceding part, living near a RAR school is not exogenous, the estimation of $\beta_{i}$ using a classical OLS regression is biased. It would partly capture the fact that the population of pupils living near a RAR junior high school would have different potential outcomes than other pupils, even in the absence of treatment. Our identification strategy consists in using the eligibility thresholds to assess causality. More precisely, the principle of our identification strategy is the following: pupils living near a public junior high school which is above the eligibility thresholds have a higher probability that their closest (default option) school is a RAR. Some pupils would thus be treated exogenously, because their closest public junior high school is above the threshold. We thus use a regression discontinuity framework.

In a preceding work, Beffy and Davezies (2013) showed that the probability for a school to enter the RAR program increases discontinuously above the $10 \%$ and $67 \%$ eligibility thresholds. Not every school above the thresholds entered the program and some schools below the thresholds entered it, so the discontinuity is fuzzy. We use this result to construct a fuzzy regression discontinuity analysis at the pupil level.

Figure 1 highlights two clear discontinuities in the individual probability that the closest public junior high school is a RAR around the $10 \%$ threshold of repeaters in the nearest public junior high school and around the $67 \%$ of pupils from disadvantaged backgrounds in the nearest public junior high school. Under the assumption that pupils living near a junior high school just below and just above the eligibility thresholds are similar, then any discontinuity in the individual outcome around the thresholds may be interpreted as a causal effect of the proximity of a RAR school.

We consider the two discontinuities separately and thus we analyze the effect of the treatment on two sub-populations around the thresholds. Figure 2 illustrates the two regions we will consider for a given bandwidth around the thresholds. In other words, we will estimate two effects : the effect of the treatment on school choice around the $10 \%$ threshold of repeaters in the nearest school (discontinuity $d^{L}$ in Figure 2 ) and the effect of the treat- 
ment on school choice around the $67 \%$ threshold of pupils from disadvantaged background in the nearest school (discontinuity $\left.d^{F}\right){ }^{8}$

Figure 1: Individual probability that the nearest junior high school is RAR

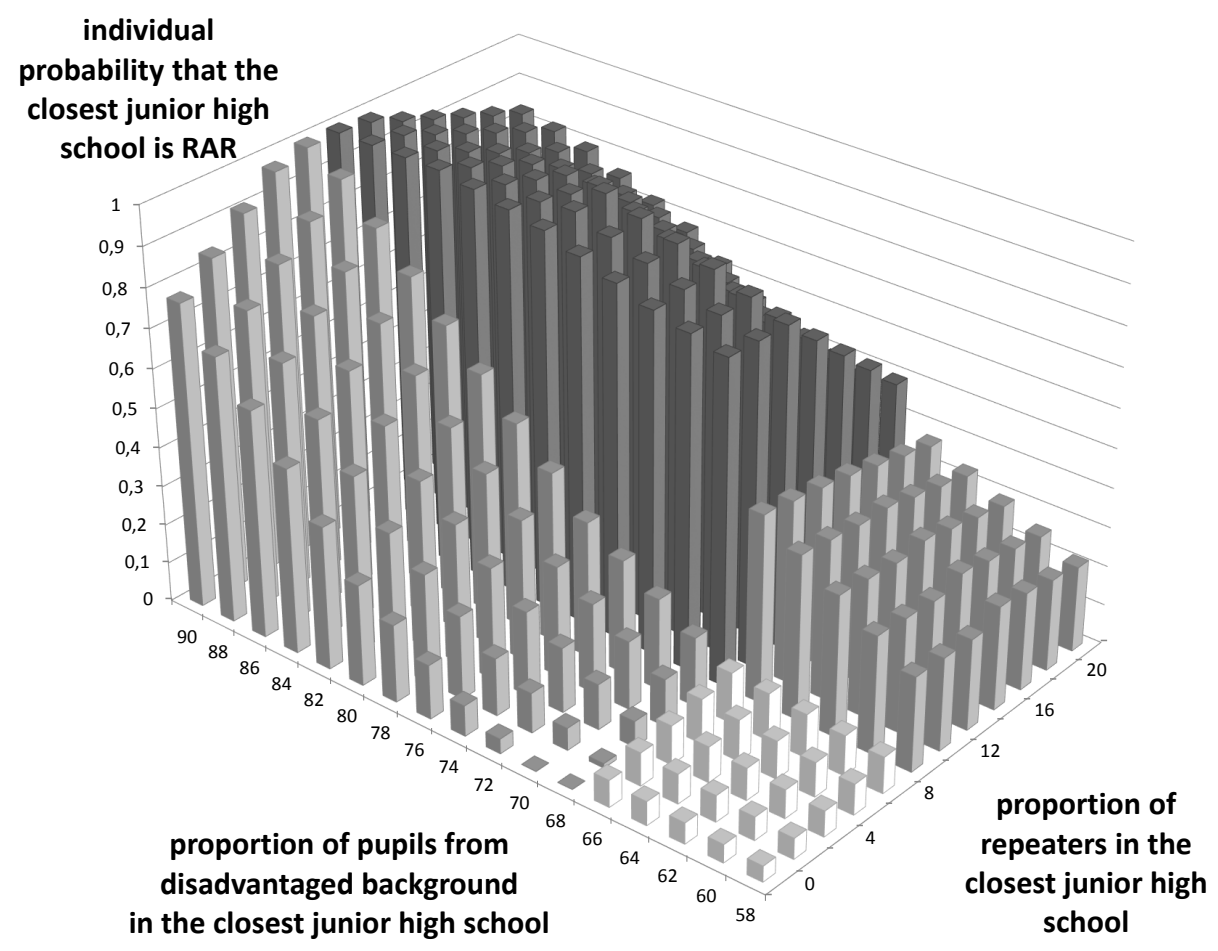

Source : MEN-MESR DEPP, FAERE 2006 and 2007

Note : The graph presents on the $\mathrm{x}$-axis the proportion of pupils from disadvantaged background in the nearest junior high school, on the z-axis the proportion of pupils who have repeated twice or more in the nearest junior high schools and on the $y$-axis the individual probability that the nearest junior high school is RAR (estimated by a local linear regression in each quadrants).

Let us define for each individual $i Z_{i}^{L}$ the proportion of pupils who have repeated twice or more in pupil $i$ 's nearest public junior high school and $Z_{i}^{F}$ the proportion of pupils from disadvantaged background in pupil $i$ 's nearest public junior high school. The individual probability to live near a RAR is discontinuous in $\left(Z^{L}, Z^{F}\right)$ at the thresholds $c^{L}=10 \%$ et $c^{F}=67 \%$ respectively. Assignment to treatment is not deterministic ; not all units move from non participation to participation above the threshold, but the probability jumps discontinuously at the threshold (fuzzy design).

These discontinuities identify the existence of "compliers" (cf. Imbens et Angrist, 1994; Hahn et al., 2001; Imbens et Lemieux, 2008), i.e. pupils who live near a RAR junior high school (respectively not) just because their closest school is above (respectively just below)

\footnotetext{
${ }^{8}$ We could alternatively consider both discontinuities at the same time. In this case, we would consider a two-dimensional assignment "boundary" and compare pupils just above and just below this assignment boundary. However, our preferred specification is to make two separate estimations, because comparing pupils below and above the boundary might lead us to compare pupils from very different neighborhoods (one in the North-West quarter of the $\left(Z^{L}, Z^{F}\right)$ graph and one in the South-East quarter for instance).
} 
Figure 2: Illustration of a window around the eligibility thresholds

(a) Discontinuity $d^{L}$

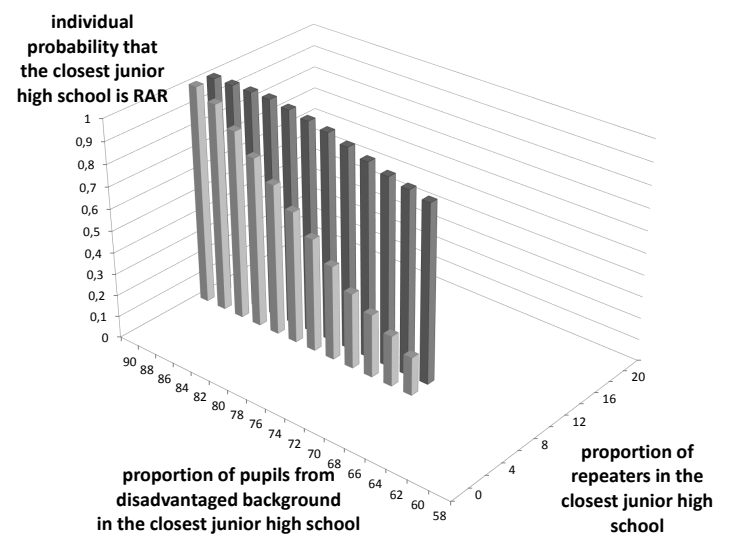

(b) Discontinuity $d^{F}$



Source : MEN-MESR DEPP, FAERE 2006 and 2007

the threshold. Those pupils are treated (or not) exogenously. ${ }^{9}$

For the population of compliers, the local average treatment effect at the cutoff values is:

$$
L A T E_{j}=E\left(Y(1)-Y(0) \mid Z^{j}=c^{j}\right), j \in\{L, F\}
$$

Note that this identifies the average treatment effect only locally, for pupils who are treated because their nearest school is just above the threshold and who would not have been treated otherwise.

Under the assumption that $\left(z^{F}, z^{L}\right) \mapsto \mathbb{E}\left(Y(j) \mid Z^{F}=z^{F}, Z^{L}=z^{L}\right)$ is continuous for $j=0,1$, these parameters are identified by the Wald ratio of the jump in the conditional expectation of the outcome to the jump in the conditional expectation in the treatment indicator: :

$$
L A T E_{J}=\frac{\lim _{z^{J} \downarrow c^{J}} \mathbb{E}\left(Y \mid Z^{J}=z^{J}, Z^{K} \in I_{K}\right)-\lim _{z^{J} \uparrow c^{J}} \mathbb{E}\left(Y \mid Z^{J}=z^{J}, Z^{K} \in I_{K}\right)}{\lim _{z^{J} \downarrow c^{J}} \mathbb{E}\left(T \mid Z^{J}=z^{J}, Z^{K} \in I_{K}\right)-\lim _{z^{J} \uparrow c^{J}} \mathbb{E}\left(T \mid Z^{J}=z^{J}, Z^{K} \in I_{K}\right)},
$$

$(J, K) \in\{(L, F),(F, L)\}$

\subsection{Estimation}

We estimate the local average treatment effects with a two stage least square estimator around the thresholds (Hahn, Todd et Van der Klaauw (2001)). More precisely, we estimate the following equation by two stage least squares:

$$
Y_{i}=\alpha+\beta T_{i}+\gamma^{\prime} V_{i}+\varepsilon_{i}
$$

where $T_{i}$ is considered endogenous and instrumented by $\mathbb{1}\left\{Z_{i}^{j}>c^{j}\right\}, j \in\{L, F\}$.

\footnotetext{
${ }^{9}$ More formally, compliers are individuals such that $\lim _{z \uparrow c} T_{i}(x)=0$ and $\lim _{z \downarrow c} T_{i}(x)=1$. This corresponds to the subgroup of individuals for whom treatment changes discontinuously at the threshold.
} 
We include the additional covariates : $V_{i}=\left(\begin{array}{c}\mathbb{1}\left\{Z_{i}^{j}<c^{j}\right\}\left(Z_{i}^{j}-c^{j}\right) \\ \mathbb{1}\left\{Z_{i}^{j} \geq c^{j}\right\}\left(Z_{i}^{j}-c^{j}\right)\end{array}\right), j \in\{L, F\}$ in order to allow the slope coefficient to be different on each side of the cutoff. This aims at limiting the asymptotic bias of nonparametric estimators (Imbens \& Lemieux, 2007).

As mentioned earlier, we estimate the model separately around each discontinuity. More precisely, we estimate equation (1) by 2SLS:

1. for observations such that $Z^{L} \in\left[10-h_{L}, 10+h_{L}\right]$ and $63 \leq Z^{F} \leq 90^{10}$

2. for observations such that $Z^{F} \in\left[67-h_{F}, 67+h_{F}\right]$ and $Z^{L} \geq 10$

where $h_{L}$ and $h_{F}$ are bandwidths around the thresholds. ${ }^{11}$

In a second part, to assess possible heterogenous effects in the population, we will consider that the treatment effect can be different across some sub-populations. To do so, we interact the treatment variable with some covariates. Let us note $X_{i}$ the dummy variable that corresponds alternatively to the scholarship status of pupil $i$, pupil's $i$ origin (born French or not), or being from a disadvantaged background or not. The regression equation becomes :

$$
Y_{i}=\alpha+\beta_{1} T_{i} \times\left(1-X_{i}\right)+\beta_{2} T_{i} \times X_{i}+\beta_{3} X_{i}+\gamma_{1}^{\prime} V_{i}+\gamma_{2}^{\prime}\left(V_{i} \times X_{i}\right)+\varepsilon_{i}
$$

where $T_{i} \times\left(1-X_{i}\right)$ and $T_{i} \times X_{i}$ are instrumented by $\mathbb{1}\left\{Z^{j}>c^{j}\right\} \times\left(1-X_{i}\right)$ and $\mathbb{1}\left\{Z^{j}>\right.$ $\left.c^{j}\right\} \times X_{i}$. In that case, we are interested in the terms $\beta_{1}$ and $\beta_{2}$, which represent the effect of living near a RAR school on the sub-population of pupils such that $X=0$ and on the sub-population of pupils such that $X=1$ respectively. In order to test for heterogenous effects between those two sub-populations, we will test for $H_{0}: \beta_{1}=\beta_{2}$.

\subsection{Manipulation of the forcing variables}

Regression discontinuity designs rely on the assumption that the forcing variable $Z$ is continuous around the threshold $\left(\left(z^{F}, z^{L}\right) \mapsto \mathbb{E}\left(Y(j) \mid Z^{F}=z^{F}, Z^{L}=z^{L}\right)\right.$ is continuous for $j=0,1)$. In particular, it means that individuals cannot manipulate the forcing variable, so that there would be significantly more observations above (or below) the threshold. In our case, remember that the selection variables are the proportion of repeaters in the nearest public junior high school and the proportion of pupils from disadvantaged background in the nearest public junior high school. Both variables were measured during the school year 2004-2005. Manipulation of these variables would mean either that the heads of junior high schools manipulated this information, or that families moved according to it in order to live closer to a school being above (or below) the thresholds.

\footnotetext{
${ }^{10}$ We restrict the sample around $Z^{F}$ because there is no discontinuity in $Z^{L}$ outside of this interval. This interval was chosen so as to have a genuine discontinuity in $Z^{L}$ without losing too many observations.

${ }^{11}$ We tested for the robustness of our estimates to the bandwidth choice. For each discontinuity, three fixed bandwidths are used. We also estimated the effects using the optimal bandwidth (Imbens and Kalyanaraman (2009)) for each outcome, twice and half the size of the optimal bandwidth (results are available on request). The results are robust to the bandwidth choice.
} 
Both possibilities are very unlikely. First, it would mean that the heads of junior high schools were aware in 2004 of both the measures and the cutoff values that would be chosen as eligibility criteria two years later, in 2006. Alternatively, it would mean that families knew whether the nearest junior high school was below or above the thresholds and would have move closer to another school accordingly. Because the eligibility criteria and the thresholds were arbitrarily selected by the French Education Ministry so as to account for $5 \%$ of pupils and because they were never made public, this seems very implausible. For those reasons, we do not believe that the forcing variables may have been manipulated.

This is supported by empirical evidence. We tested for possible discontinuities in the conditional density of forcing variables. Figure 3 presents the local linear density estimates for both selection variables below and above the thresholds, as proposed by McCrary (2008). Would headmasters have misreported the proportion of pupils being late or coming from disadvantaged background in 2004 in order for their school to enter the program, we would see many observations above the cutoff value, and few below. In the same way, would families have moved closer to a school just below the threshold to be closer to a RAR school, we would see a jump at the cutoff. We do not see any significant discontinuity around the thresholds.

Figure 3: McCrary Density Test

(a) Forcing variable $Z^{L}$

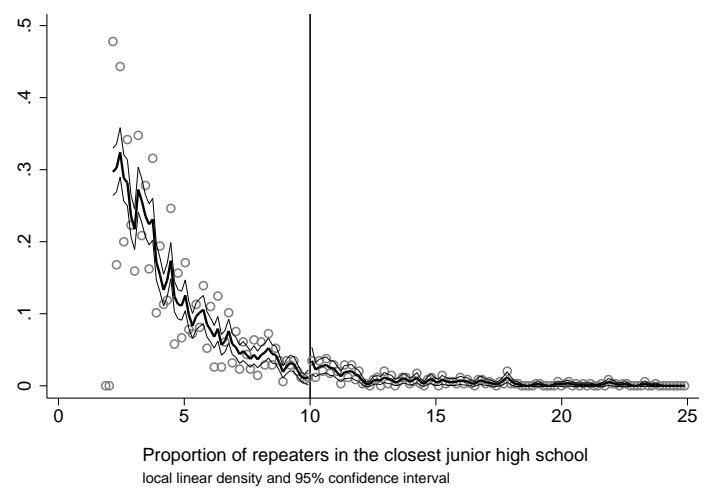

Source : MEN-MESR DEPP, FAERE (b) Forcing variable $Z^{F}$

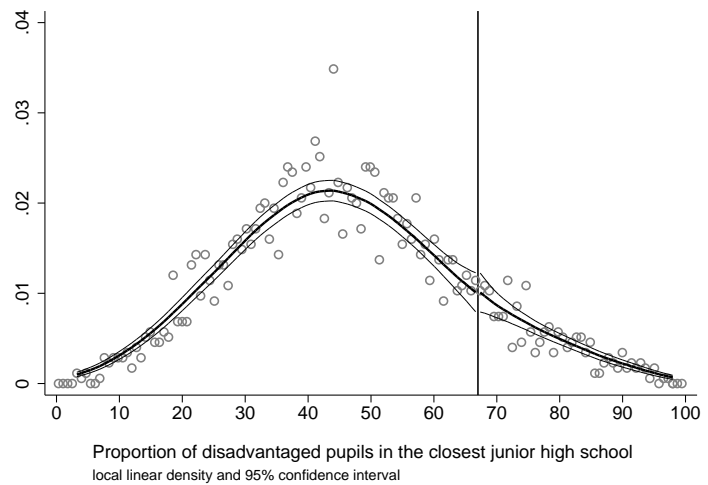

\section{Results}

We analyze the impact of the RAR program on each possible school choice pupils face when entering 6th grade, i.e. enrolling in the nearest school, in another public school or in a private school. Table 3 presents the results of the two stage least square estimations around each discontinuity. The effects are estimated for different bandwidths $h$ around each threshold.

The first stage estimates are consistent with the validity of our strategy; whatever the bandwidth, the coefficients corresponding to $\mathbb{1}\left\{Z_{i}^{L}>10\right\}$ and $\mathbb{1}\left\{Z_{i}^{F}>67\right\}$ respectively 
are highly significant in the first stage regression. Living near a public junior high school where the proportion of repeaters is above the $10 \%$ threshold significantly increases by 26 to 84 percentage points the individual probability that the closest junior high school is a RAR. This corresponds to the proportion of pupils whose closest junior high school is a RAR exogenously, due to the fact that their closest school is just above the threshold and who would not live close to a RAR otherwise. The effect of living near a RAR is then estimated on those pupils (i.e. the compliers) in the second stage. The same results hold when the proportion of pupils from disadvantaged background in the nearest school is above the $67 \%$ threshold. Moreover F-statistics are always well above the rule of thumb value of 10 .

Note that for a sufficiently small bandwidth $(h=0.5)$, the first stage estimates are 1 , meaning that assignment to treatment is deterministic above the threshold: all schools above the threshold are RAR and no school below the threshold is RAR. ${ }^{12}$ In that case, the proportion of compliers is $100 \%$ and we don't have to use a two stage least square estimation; we can directly regress the outcome variable on being above the threshold. This is displayed in the first column (for $d^{L}$ ) and in the fifth column (for $d^{F}$ ) of Table 3. The remaining columns present the second stage estimates for different larger sizes of the bandwidth. For sake of clarity, we only present the coefficient corresponding to the treatment dummy $T$, i.e. living near a RAR junior high school, in the table.

When significant, these estimates are negative for enrollment in the nearest school and in another public school and positive for enrollment in a private school. If one consider the first column of Table 3, the results suggest that living near a RAR junior high school decreases the probability to attend this school by 30 percentage points and increases the probability to attend a private school by 22 percentage points, for pupils who are treated exogenously because their closest school is just above the $10 \%$ threshold of repeaters. The fifth column of Table 3 suggests that living near a RAR junior high school decreases the probability to enroll in another public school than the closest one by 24 percentage points and increases the probability to enroll in a private school by 30 percentage points, for pupils who are treated exogenously because their closest school is just above the $67 \%$ threshold of pupils from a disadvantaged background. These results turn not significant when we increase the size of the bandwidth to $h=1, h=2$ and $h=4$. But since the bias is expected to increase with the size of the bandwidth, our preferred specification should be the smallest bandwidth one.

These results mean that living near a RAR junior high school tend to decrease the individual probability to attend the default option junior high school (the closest one) as well as the probability to go to another public school and to increase the individual probability to attend a private school, for the population of compliers. This suggests that individuals tend to avoid schools that enter the RAR program by enrolling in the private sector.

In order to better understand these averaged results, we turn to the estimation of heterogenous effects in the population of compliers. Table 4 presents the results when we

\footnotetext{
${ }^{12}$ See Appendix A for an illustration in the case of discontinuity $d^{L}$.
} 
Table 3: Estimation of the effect of living near a RAR junior high school on school choice

\begin{tabular}{|c|c|c|c|c|c|c|c|c|}
\hline & \multicolumn{4}{|c|}{ RD around the $10 \%$ threshold } & \multicolumn{4}{|c|}{ RD around the $67 \%$ threshold } \\
\hline & $\mathrm{h}=0.5$ & $h=1$ & $h=2$ & $\mathrm{~h}=4$ & $\mathrm{~h}=0.5$ & $h=1$ & $\mathrm{~h}=2$ & $\mathrm{~h}=4$ \\
\hline & \multicolumn{8}{|c|}{ Second stage } \\
\hline \multicolumn{9}{|c|}{$Y=$ Enrollment in the nearest school } \\
\hline$T$ & $\begin{array}{c}-0.30^{* * *} \\
(0.07)\end{array}$ & $\begin{array}{c}-0.46^{* * *} \\
(0.17)\end{array}$ & $\begin{array}{c}0.05 \\
(0.13)\end{array}$ & $\begin{array}{c}0.13 \\
(0.23)\end{array}$ & $\begin{array}{l}-0.06 \\
(0.10)\end{array}$ & $\begin{array}{c}0.05 \\
(0.12)\end{array}$ & $\begin{array}{c}0.08 \\
(0.23)\end{array}$ & $\begin{array}{l}-0.29 \\
(0.20)\end{array}$ \\
\hline \multicolumn{9}{|c|}{$Y=$ Enrollment in another public school } \\
\hline$T$ & $\begin{array}{c}0.08 \\
(0.06)\end{array}$ & $\begin{array}{c}0.12 \\
(0.15)\end{array}$ & $\begin{array}{l}-0.15 \\
(0.14)\end{array}$ & $\begin{array}{l}-0.39 \\
(0.27)\end{array}$ & $\begin{array}{c}-0.24^{* * *} \\
(0.04)\end{array}$ & $\begin{array}{l}-0.04 \\
(0.12)\end{array}$ & $\begin{array}{l}-0.01 \\
(0.19)\end{array}$ & $\begin{array}{l}-0.08 \\
(0.16)\end{array}$ \\
\hline \multicolumn{9}{|c|}{$Y=$ Enrollment in a private school } \\
\hline$T$ & $\begin{array}{c}0.22^{* *} \\
(0.08) \\
\end{array}$ & $\begin{array}{c}0.34 \\
(0.21) \\
\end{array}$ & $\begin{array}{c}0.10 \\
(0.11)\end{array}$ & $\begin{array}{c}0.26 \\
(0.25)\end{array}$ & $\begin{array}{c}0.30^{* *} \\
(0.10) \\
\end{array}$ & $\begin{array}{l}-0.01 \\
(0.11) \\
\end{array}$ & $\begin{array}{l}-0.07 \\
(0.13) \\
\end{array}$ & $\begin{array}{l}0.38^{*} \\
(0.20)\end{array}$ \\
\hline & \multicolumn{8}{|c|}{ First stage } \\
\hline $\mathbb{1}\left\{Z^{j}>c^{j}\right\}$ & $\begin{array}{c}1.00^{* * *} \\
(0.00)\end{array}$ & $\begin{array}{l}0.84^{* *} \\
(0.32)\end{array}$ & $\begin{array}{c}0.79^{* * *} \\
(0.21)\end{array}$ & $\begin{array}{c}0.26^{* *} \\
(0.12)\end{array}$ & $\begin{array}{c}1.00^{* * *} \\
(0.00)\end{array}$ & $\begin{array}{c}1.12^{* * *} \\
(0.34)\end{array}$ & $\begin{array}{l}0.74^{* *} \\
(0.31)\end{array}$ & $\begin{array}{c}0.63^{* * *} \\
(0.21)\end{array}$ \\
\hline F-stat & . & 572 & 1,624 & 503 & . & 687 & 415 & 1,000 \\
\hline Nbr obs & 1,778 & 6,671 & 15,441 & 30,368 & 728 & 1,481 & 2,548 & 5,602 \\
\hline Nbr clusters & 24 & 68 & 150 & 298 & 8 & 18 & 30 & 58 \\
\hline
\end{tabular}

Source: MEN-MESR DEPP, FAERE 2006 and 2007

Note: $*(\mathrm{p}<0.10),{ }^{* *}(\mathrm{p}<0.05),{ }^{* * *}(\mathrm{p}<0.01)$. Standard errors in brackets are clustered at the closest junior high school level. Two stage least squares are estimated for different bandwidths of size $\mathrm{h}$ around each threshold.

Lecture: Pupils living near a RAR junior high school exogenously, due to the fact that their closest public junior high school is above the $10 \%$ threshold of repeaters, have a 10 to 34 percentage point higher probability to enroll in a private school than pupils whose closest public junior high school is not a RAR exogenously. This difference is significant at the $5 \%$ significance level for the smallest window around the $10 \%$ threshold.

allow living near a RAR school to have differentiated effects in the sample according to observed social characteristics. More precisely, we consider that the effect of living near a RAR school can be different between pupils who benefit from a scholarship and pupils who don't. Then we consider that the treatment effect can be differentiated according to pupils' origin (Born French or not), and then whether they come from a disadvantaged background or not. For sake of simplicity, we present only the results estimated around discontinuity $d^{L}$ (the results around discontinuity $d^{F}$ are displayed in Appendix B) and only the coefficients corresponding to the treatment dummy interacted with $(1-X)$ and with $X$ respectively, for the three different covariates we just mentioned. For each outcome, the first column gives again the results where everyone is treated above the threshold and the three remaining columns present the second stage estimates for different sizes of the bandwidth.

For the sub-population of pupils who don't benefit from a scholarship, we find that living near a RAR junior high school due to the $10 \%$ threshold decreases the probability to attend the closest school (by 13 to 99 percentage points depending on the bandwidth size). This 
effect is highly significant for the two smallest bandwidths. There is no significant effect for the sub-population of pupils who benefit from a scholarship. The difference of the effect between scholarship and non scholarship pupils is significant at the $5 \%$ level for all bandwidths but the larger one. The estimated effect is quantitatively the same for pupils who don't come from a disadvantaged background. Again, there is no significant effect for pupils who come from a disadvantaged background. The difference between those two sub-populations is also significant at the $5 \%$ level for all bandwidths but the larger one.

There is no clear effect on the probability to enroll in another public school, considering that the sign of the coefficient changes when the size of the bandwidth increases.

The probability to enroll in a private school increases significantly when pupils live near a RAR school due to the $10 \%$ threshold for the sub-population of pupils who don't benefit from a scholarship and for the sub-population of pupils who don't come from a disadvantaged background. In particular, for the sub-population of pupils who don't come from a disadvantaged background, living near a RAR junior high school due to the $10 \%$ threshold significantly increases by 27 to 63 percentage points the probability to enroll in the private sector, whereas their is no significant effect for the sub-population of pupils from a disadvantaged background.

These results highlight the mechanisms underlying individual school choice. It seems that the most socially advantaged individuals tend to avoid schools that enter the RAR program more than other pupils, by enrolling in the private sector instead. 
Table 4: Estimation of heterogenous effects of living near a RAR on school choice $\left(d^{L}\right)$

\begin{tabular}{|c|c|c|c|c|c|c|c|c|c|c|c|c|}
\hline \multirow[t]{3}{*}{$\mathrm{Y}=$ Enrollment in } & \multicolumn{4}{|c|}{ the nearest school } & \multicolumn{4}{|c|}{ another public school } & \multicolumn{4}{|c|}{ a private school } \\
\hline & \multicolumn{12}{|c|}{ RD around the $10 \%$ threshold } \\
\hline & $\mathrm{h}=0.5$ & $\mathrm{~h}=1$ & $\mathrm{~h}=2$ & $\mathrm{~h}=4$ & $\mathrm{~h}=0.5$ & $\mathrm{~h}=1$ & $\mathrm{~h}=2$ & $\mathrm{~h}=4$ & $\mathrm{~h}=0.5$ & $\mathrm{~h}=1$ & $\mathrm{~h}=2$ & $\mathrm{~h}=4$ \\
\hline \multicolumn{13}{|c|}{$X=$ Scholarship $($ ref. $=$ no $)$} \\
\hline$X=0$ & $\begin{array}{c}-0.61^{* * *} \\
(0.09)\end{array}$ & $\begin{array}{c}-0.99 * * * \\
(0.30)\end{array}$ & $\begin{array}{l}-0.13 \\
(0.14)\end{array}$ & $\begin{array}{l}-0.15 \\
(0.17)\end{array}$ & $\begin{array}{c}0.22^{* * *} \\
(0.06)\end{array}$ & $\begin{array}{c}0.39 * * * \\
(0.13)\end{array}$ & $\begin{array}{l}-0.07 \\
(0.13)\end{array}$ & $\begin{array}{l}-0.19 \\
(0.18)\end{array}$ & $\begin{array}{c}0.40 * * * \\
(0.12)\end{array}$ & $\begin{array}{c}0.60 * * \\
(0.30)\end{array}$ & $\begin{array}{c}0.20 \\
(0.14)\end{array}$ & $\begin{array}{c}0.34 \\
(0.21)\end{array}$ \\
\hline$X=1$ & $\begin{array}{c}0.12 \\
(0.28)\end{array}$ & $\begin{array}{c}0.17 \\
(0.29)\end{array}$ & $\begin{array}{l}0.34^{*} \\
(0.20)\end{array}$ & $\begin{array}{c}1.62 \\
(1.88)\end{array}$ & $\begin{array}{l}-0.18 \\
(0.28)\end{array}$ & $\begin{array}{l}-0.22 \\
(0.32)\end{array}$ & $\begin{array}{l}-0.28 \\
(0.20)\end{array}$ & $\begin{array}{l}-1.36 \\
(1.66)\end{array}$ & $\begin{array}{c}0.06^{* *} \\
(0.03)\end{array}$ & $\begin{array}{c}0.05 \\
(0.05)\end{array}$ & $\begin{array}{l}-0.06 \\
(0.09)\end{array}$ & $\begin{array}{l}-0.26 \\
(0.40)\end{array}$ \\
\hline Test (pvalue) & 0.030 & 0.033 & 0.032 & 0.345 & 0.163 & 0.068 & 0.224 & 0.456 & 0.006 & 0.054 & 0.054 & 0.176 \\
\hline Nbr obs & 1,778 & 6,671 & 15,441 & 30,368 & 1,778 & 6,671 & 15,441 & 30,368 & 1,778 & 6,671 & 15,441 & 30,368 \\
\hline Nbr clusters & 24 & 68 & 150 & 298 & 24 & 68 & 150 & 298 & 24 & 68 & 150 & 298 \\
\hline \multicolumn{13}{|c|}{$X=$ Born French $($ ref. $=$ no $)$} \\
\hline$X=0$ & $\begin{array}{c}-0.25^{* *} \\
(0.11)\end{array}$ & $\begin{array}{c}1.66 \\
(8.25)\end{array}$ & $\begin{array}{c}1.82 \\
(1.37)\end{array}$ & $\begin{array}{c}-24.96 \\
(260.78)\end{array}$ & $\begin{array}{c}0.05 \\
(0.08)\end{array}$ & $\begin{array}{c}-3.31 \\
(14.51)\end{array}$ & $\begin{array}{l}-1.90 \\
(1.46)\end{array}$ & $\begin{array}{c}23.65 \\
(246.26)\end{array}$ & $\begin{array}{c}0.20^{* *} \\
(0.09)\end{array}$ & $\begin{array}{c}1.65 \\
(6.35)\end{array}$ & $\begin{array}{c}0.07 \\
(0.14)\end{array}$ & $\begin{array}{c}1.31 \\
(14.70)\end{array}$ \\
\hline$X=1$ & $\begin{array}{c}-0.32^{* * *} \\
(0.07)\end{array}$ & $\begin{array}{c}-0.48^{* * *} \\
(0.17)\end{array}$ & $\begin{array}{c}0.00 \\
(0.12)\end{array}$ & $\begin{array}{c}0.05 \\
(0.21)\end{array}$ & $\begin{array}{c}0.09 \\
(0.06)\end{array}$ & $\begin{array}{c}0.17 \\
(0.11)\end{array}$ & $\begin{array}{l}-0.10 \\
(0.12)\end{array}$ & $\begin{array}{l}-0.32 \\
(0.23)\end{array}$ & $\begin{array}{c}0.23^{* *} \\
(0.08)\end{array}$ & $\begin{array}{l}0.31^{*} \\
(0.18)\end{array}$ & $\begin{array}{c}0.10 \\
(0.11)\end{array}$ & $\begin{array}{c}0.27 \\
(0.25)\end{array}$ \\
\hline Test (pvalue) & 0.466 & 0.796 & 0.172 & 0.924 & 0.641 & 0.811 & 0.200 & 0.922 & 0.732 & 0.832 & 0.849 & 0.944 \\
\hline Nbr obs & 1,778 & 6,671 & 15,441 & 30,368 & 1,778 & 6,671 & 15,441 & 30,368 & 1,778 & 6,671 & 15,441 & 30,368 \\
\hline Nbr clusters & 24 & 68 & 150 & 298 & 24 & 68 & 150 & 298 & 24 & 68 & 150 & 298 \\
\hline \multicolumn{13}{|c|}{$X=$ Disadvantaged background $($ ref. $=$ no $)$} \\
\hline$X=0$ & $\begin{array}{c}-0.64^{* * *} \\
(0.12)\end{array}$ & $\begin{array}{c}-1.04^{* *} \\
(0.40)\end{array}$ & $\begin{array}{l}-0.15 \\
(0.13)\end{array}$ & $\begin{array}{l}-0.06 \\
(0.17)\end{array}$ & $\begin{array}{c}0.25^{* * *} \\
(0.09)\end{array}$ & $\begin{array}{c}0.41^{* * *} \\
(0.15)\end{array}$ & $\begin{array}{l}-0.12 \\
(0.13)\end{array}$ & $\begin{array}{c}-0.39^{*} \\
(0.22)\end{array}$ & $\begin{array}{c}0.39 * * * \\
(0.12)\end{array}$ & $\begin{array}{l}0.63^{*} \\
(0.38)\end{array}$ & $\begin{array}{c}0.27^{*} \\
(0.16)\end{array}$ & $\begin{array}{l}0.46^{*} \\
(0.26)\end{array}$ \\
\hline$X=1$ & $\begin{array}{c}0.00 \\
(0.13)\end{array}$ & $\begin{array}{l}-0.05 \\
(0.17)\end{array}$ & $\begin{array}{c}0.26 \\
(0.17)\end{array}$ & $\begin{array}{c}0.62 \\
(0.49)\end{array}$ & $\begin{array}{l}-0.03 \\
(0.11)\end{array}$ & $\begin{array}{l}-0.07 \\
(0.21)\end{array}$ & $\begin{array}{l}-0.16 \\
(0.17)\end{array}$ & $\begin{array}{l}-0.48 \\
(0.45)\end{array}$ & $\begin{array}{c}0.03 \\
(0.06)\end{array}$ & $\begin{array}{c}0.12 \\
(0.09)\end{array}$ & $\begin{array}{l}-0.09 \\
(0.08)\end{array}$ & $\begin{array}{l}-0.14 \\
(0.20)\end{array}$ \\
\hline Test (pvalue) & 0.006 & 0.050 & 0.022 & 0.136 & 0.147 & 0.083 & 0.747 & 0.801 & 0.001 & 0.094 & 0.008 & 0.021 \\
\hline Nbr obs & 1,713 & 6,473 & 14,887 & 29,336 & 1,713 & 6,473 & 14,887 & 29,336 & 1,713 & 6,473 & 14,887 & 29,336 \\
\hline Nbr clusters & 24 & 68 & 150 & 298 & 24 & 68 & 150 & 298 & 24 & 68 & 150 & 298 \\
\hline
\end{tabular}

Source: MEN-MESR DEPP, FAERE 2006 and 2007

Note: $*(\mathrm{p}<0.10),{ }^{* *}(\mathrm{p}<0.05),{ }^{* * *}(\mathrm{p}<0.01)$. Standard errors in brackets are clustered at the closest junior high school level. Two stage least squares are estimated for different bandwidths of size $\mathrm{h}$ around the threshold.

Lecture: Scholarship pupils who live near a RAR junior high school exogenously, due to the fact that their closest public junior high school is just above the $10 \%$ threshold $(\mathrm{h}=0.5)$, have a 6 percentage point higher probability to enroll in a private junior high school than scholarship pupils whose nearest junior high school is not a RAR exogenously. Non scholarship pupils who live near a RAR junior high school exogenously, due to the fact that their closest public junior high school is just above the $10 \%$ threshold, have a 40 percentage point higher probability to enroll in a private junior high school than non scholarship pupils whose nearest junior high school is not a RAR exogenously. The difference between these two estimates is significantly different from zero. 


\section{Conclusion}

Our goal was to identify the effect of place-based compensatory education on individual sorting across schools. To do so, we have estimated the causal impact of the RAR program on school choice. Using an original geocoded data base and a reliable identification strategy, we find that the RAR program increases the individual probability to attend a private school for pupils living near a RAR school exogenously, due to the eligibility scheme. We find that the effect is heterogenous with respect to social characteristics; pupils from more advantaged backgrounds have a smaller probability to enroll in their closest school and a higher probability to attend a private school than other pupils.

Our findings are true locally, for pupils who live near a RAR school because their closest school is above the thresholds. They cannot be generalized to the overall population. But they show that sorting effects do exist and that they are not negligible. Since we are comparing pupils living near schools just below and just above the eligibility thresholds, we compare a priori pupils in the vicinity of schools being at the margin of eligibility. It means that the schools we consider are the less disadvantaged ones, according to eligibility criteria. We could speculate that, if sorting exists in relatively less deprived areas, it could be even higher in more disadvantaged ones.

These results may shed new light on how to evaluate place-based education policies. They make clear that it is very important to take individual sorting into account. Individuals do adjust to school-based education policies by changing schools; these adjustments are quick; they are potentially of large magnitude and they are not random in the population. Not only treated individuals are different ex ante with respect to the general population (selection bias), but they may also select themselves into (or out of) treated schools or treated zones resulting in a sorting bias. These findings may thus help explain some results of the literature; sorting effects may be a reason why empirical studies fail to find positive effects or even find negative effects of compensatory education in secondary education. If socially more advantaged pupils are more likely to avoid treated schools, then the effect of the treatment is estimated on the less advantaged ones. And if socially less advantaged pupils have poorer academic performance on average, then the estimated average treatment effect is negative. This provides material for future research. First, one need to control for individual sorting when evaluating place-based policies. Second, one may want to further investigate the part due to endogenous sorting. Third, one need to examine the existence of dynamic peer effects.

On one hand, endogenous sorting may create adverse effects by increasing social segregation across schools. If socially more advantaged pupils (who are probably academically more advantaged on average) avoid treated schools, then those schools loose potentially "good" peers, which would be detrimental to treated pupils. But on the other hand, it could be that sorting effects lead to better target the pupils most in need of the program. Maybe those pupils are better off if only they benefit from the program. From a public policy point of view, the interpretation of our results may thus lead to a trade-off between desirable effects and adverse effects. 


\section{References}

- M. Beffy and L. Davezies. Has the "ambition success" educational program achieved its ambition? Annals of Economics and Statistics, (111/112):271-294, 2013.

○ R. Bénabou, F. Kramarz, and C. Prost. The French zones d'éducation prioritaire: Much ado about nothing? Economics of Education Review, 28(3):345-356, 2009.

○ G. D. Borman and J. V. D'Agostino. Title I and student achievement: A meta-analysis of federal evaluation results. Educational Evaluation and Policy Analysis, 18(4):309-326, 1996.

$\circ$ J. Dewey, T. A. Husted, and L. W. Kenny. The ineffectiveness of school inputs: a product of misspecification? Economics of Education Review, 19(1):27-45, 2000.

- W. Dobbie and R. G. Fryer. Are high-quality schools enough to increase achievement among the poor? Evidence from the Harlem Children's Zone. American Economic Journal: Applied Economics, pages 158-187, 2011.

○ D. Epple, T. Romer, and H. Sieg. Interjurisdictional sorting and majority rule: an empirical analysis. Econometrica, 69(6):1437-1465, 2001.

○ G. Fack and J. Grenet. Les effets de l'assouplissement de la carte scolaire dans l'éducation prioritaire. Éducation et Formations, (83):25-37, 2013.

- M. M. Ferreyra. Estimating the effects of private school vouchers in multidistrict economies. American Economic Review, 97(3):789-817, 2007.

○ J. Hahn, P. Todd, and W. Van der Klaauw. Identification and estimation of treatment effects with a regression-discontinuity design. Econometrica, 69(1):201-09, 2001.

- E. A Hanushek. The failure of input-based schooling policies. The Economic journal, 113(485):64-98, 2003.

- Larry V. Hedges, Richard D. Laine, and Rob Greenwald. Does money matter? a metaanalysis of studies of the effects of differential school inputs on student outcomes. Educational Researcher, 23(3):5-14, 1994.

- C.-T. Hsieh and M. Urquiola. The effects of generalized school choice on achievement and stratification: Evidence from Chile's voucher program. Journal of Public Economics, 90(8-9):1477-1503, 2006.

- G. Imbens and K. Kalyanaraman. Optimal bandwidth choice for the regression discontinuity estimator. NBER Working Papers, 2009.

○ G. W. Imbens and T. Lemieux. Regression discontinuity designs: A guide to practice. Journal of Econometrics, 142(2):615-635, 2008.

- Guido W. Imbens and Joshua D. Angrist. Identification and estimation of local average treatment effects. Econometrica, 62(2):467-475, 1994. 
- A. B. Krueger. Economic considerations and class size. The Economic Journal, 113(485):34-63, 2003.

- S. Machin, S. McNally, and C. Meghir. Improving pupil performance in english secondary schools: Excellence in cities. Journal of the European Economic Association, 2(2-3):396405, 2004.

- S. Machin, S. McNally, and C. Meghir. Resources and standards in urban schools. Journal of Human Capital, 4(4):365-393, 2010.

- J. McCrary. Manipulation of the running variable in the regression discontinuity design: A density test. Journal of Econometrics, 142(2):698-714, 2008.

- T. Nechyba. Public school finance and urban school policy: General versus partial equilibrium analysis. Brookings-Wharton Papers on Urban Affairs, pages 139-170, 2003.

- D. B Rubin. Estimating causal effects of treatments in randomized and nonrandomized studies. Journal of Educational Psychology; Journal of Educational Psychology, 66(5):688-701, 1974.

- J. Shapiro and J. Moreno Treviño. Compensatory education for disadvantaged mexican students: An impact evaluation using propensity score matching. 3334, 2004.

- A. Tokman. Evaluation of the P900 Program: A Targeted Education Program for Underperforming Schools. Working Papers Central Bank of Chile 170, Central Bank of Chile, 2002.

- M. Urquiola. Does school choice lead to sorting? Evidence from tiebout variation. American Economic Review, 95(4):1310-1326, 2005.

- M. Urquiola and E. Verhoogen. Class-size caps, sorting, and the regression-discontinuity design. American Economic Review, 99(1):179-215, 2009.

- W. van der Klaauw. Breaking the link between poverty and low student achievement: An evaluation of Title I. Journal of Econometrics, 142(2):731-756, 2008. 


\section{A Sharp and fuzzy discontinuities}

Figure 4: Sharp and fuzzy discontinuity around $d^{L}$

(a) $\mathrm{h}=0.5$

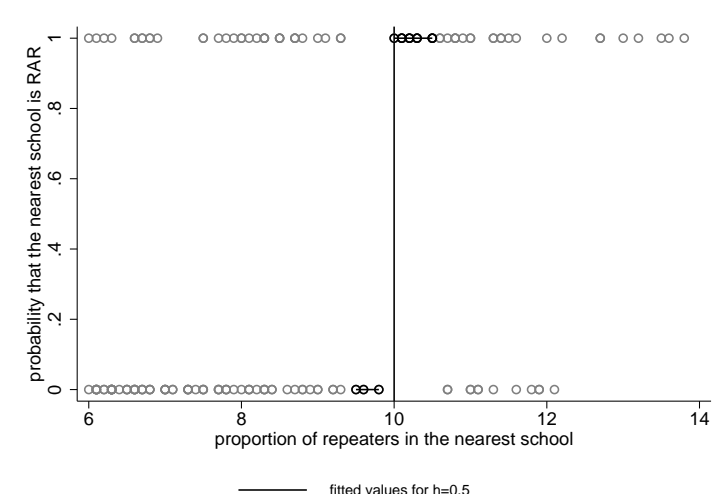

(c) $\mathrm{h}=2$

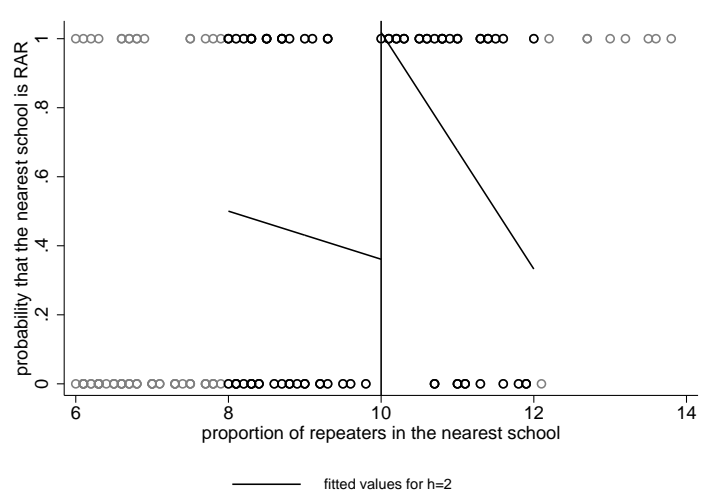

(b) $\mathrm{h}=1$

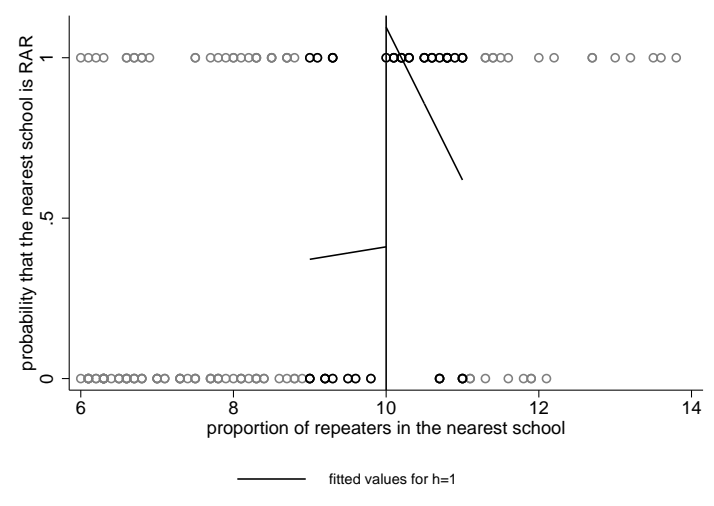

(d) $h=4$

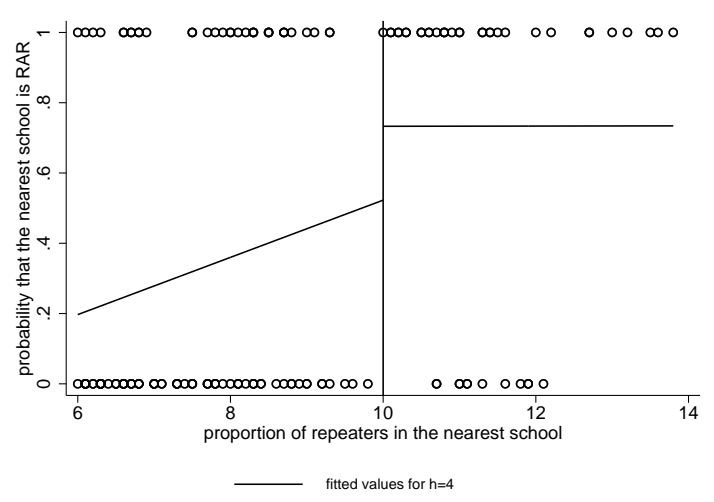

Source : MEN-MESR DEPP, FAERE 2006 and 2007

B Results around discontinuity $d^{F}$ 
Table 5: Estimation of heterogenous effects of living near a RAR on school choice around discontinuity $d^{F}$

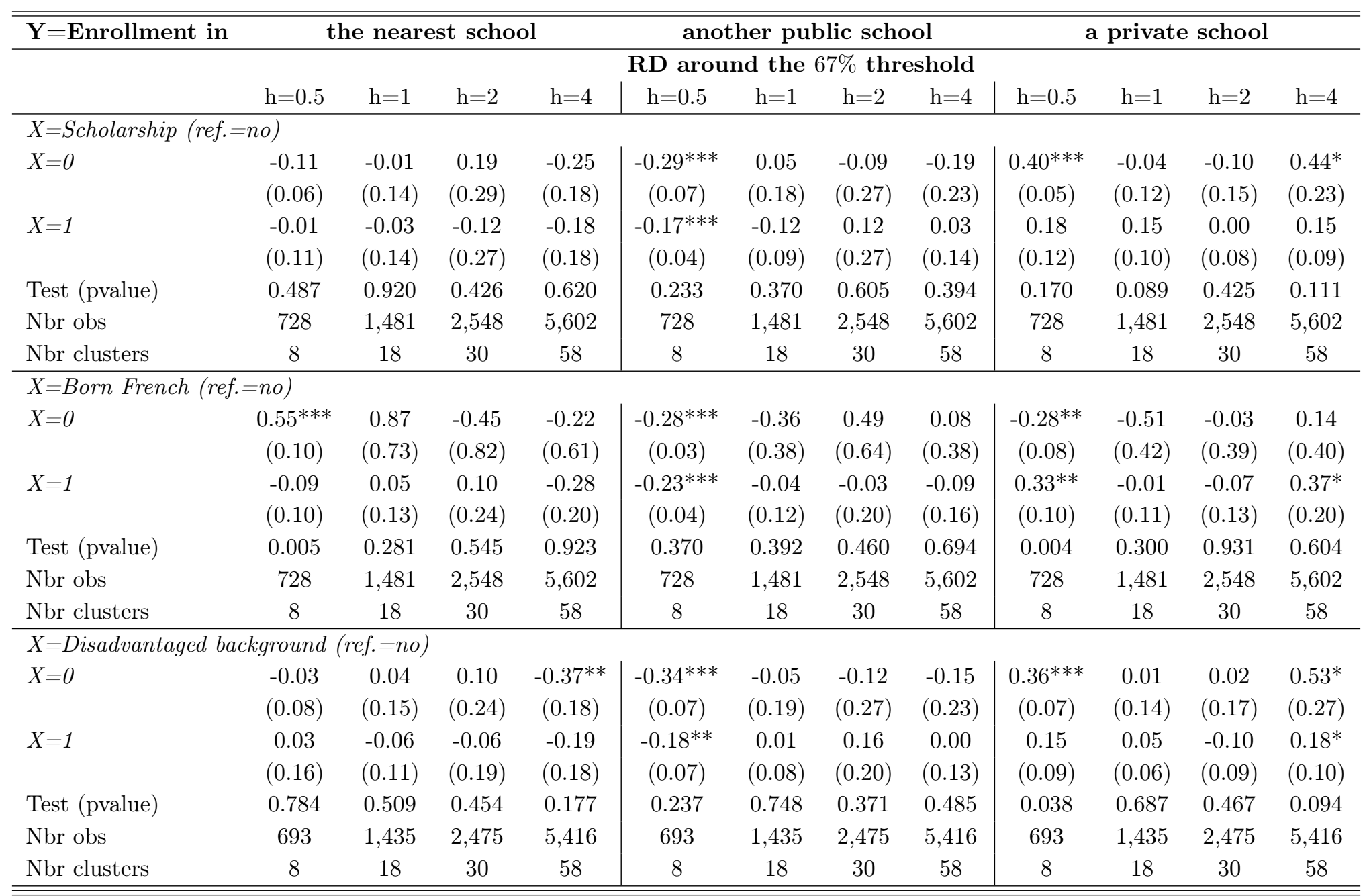

Source: MEN-MESR DEPP, FAERE 2006 and 2007

Note: $*(\mathrm{p}<0.10),{ }^{* *}(\mathrm{p}<0.05),{ }^{* * *}(\mathrm{p}<0.01)$. Standard errors in brackets are clustered at the closest junior high school level. Two stage least squares are estimated for different bandwidths of size $\mathrm{h}$ around the threshold.

Lecture: Scholarship pupils who live near a RAR junior high school exogenously, due to the fact that their closest public junior high school is just above the $67 \%$ threshold $(\mathrm{h}=0.5)$, have a 17 percentage point smaller probability to enroll in another public junior high school than scholarship pupils whose nearest junior high school is not a RAR exogenously. Non scholarship pupils who live near a RAR junior high school exogenously, due to the fact that their closest public junior high school is just above the $10 \%$ threshold, have a 29 percentage point smaller probability to enroll in another public junior high school than non scholarship pupils whose nearest junior high school is not a RAR exogenously. The difference between these two estimates is not significantly different from zero. 